\title{
EL TEMA DE LA CEGUERA EN LA LITERATURA RELIGIOSA DE LOPE
}

\author{
Hugo Lezcano Tosca
}

\begin{abstract}
Como si el mar se secasse se verían tan estraños monstros, assí, mi Dios, veo mis torpezas en las arenas de mis passados años.

LOPE DE VEGA, Soliloquios, jaculatoria XCII.
\end{abstract}

\begin{abstract}
El sentido de la vista tiene una especial importancia en el Barroco, momento histórico en el que el desengaño se convierte en un lugar común. El hombre vive en el engaño, es decir, cree que ve pero no ve. El desengaño consiste en que el hombre recupera la visión y puede darse cuenta de cómo son las cosas en realidad: el mundo es algo frágil, sus placeres, vanidad, y la única cosa cierta es que la muerte lo aguarda ${ }^{1}$. Si el sentido del oído es, desde las sirenas de Ulises, propicio al engaño, este engaño, como veremos, también puede introducirse por los ojos ${ }^{2}$.

En este trabajo vamos a estudiar la importancia de la ceguera en dos obras religiosas de Lope de Vega, las Rimas sacras (1614) y los Soliloquios (1626). En un primer momento, nos acercaremos a nuestro tema de estudio teniendo en cuenta que la ceguera llega a la literatura religiosa mediante la transformación de un tópico de la poesía petrarquista. Después

\footnotetext{
${ }^{1}$ Escribe Otis H. GreEN en España y la tradición occidental, Madrid, Gredos, 1969: «este desengaño tiene algo de aquella especie de despertar a la realidad de las cosas que debió de experimentar el Hijo Pródigo cuando exclamó: «me levantaré e iré a casa de mi padre». Este despertar de la conciencia a la realidad se llama "caer en la cuenta": sentir que se nos caen las escamas de los ojos y que vemos las cosas como son», volumen IV, p. 58. Sobre el desengaño, véase el citado estudio de Green, pp. 57-93. Gracián, Cervantes y el propio Lope dedicaron muchas páginas al desengaño. Para los dos primeros, véase el trabajo citado de O. H. Green.

${ }^{2}$ En El Peregrino en su patria se hace referencia al engaño que se produce gracias al sentido de la vista: «iCuán vanamente os parece, I y por consejo engañado, I que anochece arrebolado | el sol que en agua amanece!», p. 384. Recuérdese también el soneto de Argensola en el que se manifiesta que el cielo que vemos «ni es cielo ni es azul», comentado por Green, España y la tradición occidental, I.
}

Rlit, LXVI, 132 (2004), 389-407 
estudiamos cómo se presenta la llamada divina en la literatura religiosa, gracias a la cual el yo consigue escapar de la oscuridad. Por último, analizamos el tema de la ceguera en la tradición literaria y religiosa que se relaciona con el sistema de los Ejercicios espirituales ignacianos.

\section{LA CEGUERA EN LA POESÍA PETRARQUISTA Y SU INFLUENCIA EN LA POESÍA «A LO DIVINO»}

Desde el principio de los Soliloquios, comprobamos cómo el yo poético ha salido del engaño en la medida en que consigue «ver en lo que todo para», como se aprecia en el siguiente fragmento de la Introducción de los Soliloquios:

$$
\begin{aligned}
& \text { La razón, a quien solía } \\
& \text { bolver mi engaño la cara, } \\
& \text { viendo en lo que todo para } \\
& \text { oy al remedio me guía }{ }^{3} \text {. }
\end{aligned}
$$

Destaca la importancia del verbo «ver»; este verbo juega un papel relevante en la poética petrarquista, como estudiamos a continuación. Vamos a fijarnos en los sonetos que abren los Cancioneros de dos de los más importantes poetas del siglo XVI, Garcilaso y Herrera, así como en el primer soneto de las Rimas sacras y en la Introducción de esta misma obra. En todos estos casos, se hace mención al sentido de la vista, entendido no como la simple facultad de ver, sino como la capacidad de reflexionar sobre la propia existencia. Es significativo que se aluda a la ceguera en las composiciones que se sitúan al principio de los textos, como son la introducción y los sonetos-prólogo; se trata de composiciones que, si bien pertenecen al texto y no al paratexto, plantean no las condiciones de lectura, como sucede en el paratexto, sino el tono de las obras en las que dichas composiciones están incluidas.

El tema de la ceguera se desarrolla desde el principio de la tradición petrarquista. El yo poético avanza por el camino de sus amores creyendo ver hacia dónde llevan sus pasos, pero al cabo de cierto tiempo reconoce haberse perdido ${ }^{4}$. Así, el más petrarquista de los poetas españoles del XVI,

\footnotetext{
${ }^{3}$ Hemos editado los Soliloquios en nuestra tesis doctoral: Los Soliloquios de Lope de Vega: paratexto, género, intertextualidad y edición crítica, defendida en 2004 en la U.A.M. A la espera de la publicación de dicha edición crítica, citamos por la edición de Sancha, LOPE DE VEGA, Colección de las obras sueltas assí en prosa como en verso, Antonio de Sancha, ed. de Francisco Cerdá y Rico, Madrid, 1776-1779, tomo XVII; reimpr. por Arco Libros, Madrid, 1989.

${ }^{4}$ Recuérdese el soneto XVII de Garcilaso, «Pensando que el camino iba derecho», en el que la vista engaña al yo: «el ancho campo me parece estrecho, I la noche clara
} 
Herrera, exhibe su tenaz ceguera con orgullo: «Gasté en error la edad florida mía; I ahora veo el daño, pero tarde: I que ya mal puede ser qu'el seso guarde I a quien se entrega ciego a su porfía», Soneto I, Algunas obras, Sevilla, $1582^{5}$.

Al igual que Cupido es ciego (se le representa con una venda en los ojos) y lanza sus flechas sin saber a qué corazones alcanzan, el yo poético de la lírica petrarquista hereda la ceguera del Dios del Amor ${ }^{6}$. Pero Herrera no se arrepiente de «entregarse ciego a su porfía», sino que esto forma parte del «furor» del enamorado ${ }^{7}$. Nos interesa el primer soneto de Herrera porque da cuenta de una situación del yo poético que se vuelve a lo divino y se convierte en un tópico de la literatura religiosa.

Como señaló en su día Otis $H$. Green, en la tradición de poesía cortesana de la que el petrarquismo forma parte, es habitual que el yo poético emprenda un camino de regreso hacia Dios, después de haber dedicado buena parte de su vida a la escritura de poesía profana ${ }^{8}$. Tenemos dos sistemas poéticos diferentes, que se presentan en una oposición más teórica de efectiva, puesto que la literatura religiosa se escribe utilizando los modelos y referencias de la literatura profana. La ceguera del yo poético petrarquista se transforma a lo divino, y se convierte en la ceguera del yo pecador, de la que se escapa gracias a la ayuda de Dios.

me parece oscura (...)». Citamos por la edición de Elias RIVERS, Poesías castellanas completas, Madrid, Castalia, 1986, p. 53.

${ }^{5}$ Citamos por la edición de Cristóbal Cuevas, Poesía castellana original completa, Madrid, Cátedra, 1997, segunda edición, p. 366. Sobre la poesía de Herrera, además de la introducción de Cuevas a la edición citada, véase Begoña LóPEZ BUENo, La poesía cultista de Herrera a Góngora, Sevilla, ediciones Alfar, 1987. En la p. 38, la autora detalla las diferencias entre las ediciones de 1582 y 1619 de la poesía herreriana.

${ }^{6}$ Herrera se refiere a la imagen de Cupido y explica cada uno de sus atributos: «lo fingen armado de saetas, porque los que son heridos de sus flechas, no de otra suerte se duelen; (...). I da la razón porque los poetas lo describen ciego, es; porque el amante se engaña muchas vezes, cuando juzga de sí, o de la cosa que ama; i porque es ciego, que no considera lo que haze», Obras de Garcilaso de la Vega con anotaciones, Sevilla, Alonso de la Barrera, 1580, B.N.M. R / 5853, (fol. 115r). También puede darse el caso de que sea el llanto lo que ciegue al yo poético, como en los siguientes tercetos de Lope en El Peregrino en su patria: «Hoy, que a estos montes y a la muerte llego, I donde vine sin ti, sin alma y vida, I te escribo, de llorar cansado y ciego», ed. de Juan Bautista Avalle-Arce, Madrid, Castalia, 1973, p. 263.

7 Así se demuestra en los tercetos del Soneto I de Herrera: «Tal vez pruebo (mas, ¿qué me vale? Alçarme I del graue peso que mi cuello oprime, I aunque falta a la poca fuerça el hecho. I Sigo al fin mi furor, porque mudarme I no es onra ya, ni justo que s'estime I tan mal de quien tan bien rindió su pecho», Poesía castellana original completa, p. 356.

${ }^{8}$ En España y la tradición occidental, «El pródigo y su vuelta», Madrid, Gredos, 1969, volumen I, pp. 306-345. Green aporta numerosos ejemplos de palinodias o retractaciones poéticas de autores profanos que vuelven sus ojos a Dios, como Hernando de Acuña o Soto de Rojas. También sucede lo mismo en el caso de Francisco de Aldana, y, como vamos a estudiar, Lope de Vega. 
Continuamos con el análisis de la Introducción de las Rimas sacras, en la que el tema de la ceguera está presente a través de una referencia a Polifemo: «Cantemos el mar que vimos, I las tormentas que passamos, I los golfos que navegamos, I y el Polifemo en que dimos. I Cómo cegaste la luz I (que fue de tanta importancia) I al rostro de su arrogancia I con el leño de tu cruz?» ${ }^{9}$. Se utiliza por primera vez el concepto yo-monstruo, que volveremos a encontrar en el primer soneto de la colección, aunque en otro contexto ( $\ll$ el monstro muerto de mi ciego engaño); la ceguera consiste en este caso en que el yo literario se identifica con el personaje mitológico de Polifemo, el cual era incapaz de «ver» su fealdad cuando pretendía el amor de Galatea, hasta que finalmente vio su propio reflejo en el agua de una fuente y tuvo conciencia de su auténtico aspecto. Si la fuente permitió a Polifemo salir de su estado de ceguera, en nuestro texto es la luz de la cruz de Cristo la que acaba con la «luz» en la que el yo ha creído ver.

Como sucede habitualmente en la poesía religiosa, los motivos profanos se integran en un contexto meditativo. Así, los primeros versos del soneto I de Garcilaso, un soneto-prólogo que condiciona la lectura de su cancionero, tienen una repercusión decisiva en las Rimas sacras. Veamos primero el comienzo del soneto de Garcilaso, en el que el yo poético se detiene en medio del camino tópico del petrarquismo: «Cuando me paro a contemplar mi 'stado | y a ver los pasos por dó me han traído» ${ }^{10} \mathrm{El}$ peregrino de amor de la tradición petrarquista, cautivado por un amor no correspondido que le lleva a la deriva, es un lugar común que se desarrolla con éxito en la literatura del siglo XVII, como se comprueba en El peregrino en su patria de Lope y en las Soledades de Góngora ${ }^{11}$.

En el primer soneto de las Rimas sacras, Lope transforma a lo divino el primer soneto garcilasiano: «Cuando me paro a contemplar mi estado I y a ver los pasos por dónde he venido». Lo importante para nosotros es el verbo «ver»; Garcilaso, en el soneto I, abandona rápidamente el tema de la vista; pero en el primer soneto de las Rimas sacras, Lope lo desarrolla, puesto que el yo poético «mira» su existencia, gracias a lo cual consigue «conocer», en el segundo cuarteto del soneto I: «Cuando miro los años que

\footnotetext{
${ }^{9}$ Citamos por la siguente edición: Rimas sacras. Primera parte, Viuda de Alonso Pérez, Madrid, 1614; ed. facsímil de Joaquín de Entrambasaguas, Madrid, C.S.I.C., (Clásicos Hispánicos), 1963.

${ }^{10}$ Sobre la fortuna del soneto I de Garcilaso, véase E. Glasser, "CCuando me paro a contemplar mi estado": trayectoria de un Rechenchafts-sonnet», Estudios hispano-portugueses, Valencia, Castalia, 1957, pp. 59-95.

${ }^{11}$ En «El peregrino de amor en las Soledades de Góngora», Antonio Vilanova afirma: «Lope es, con Herrera, el más directo precursor hispánico de la poesía de la soledad y de la peregrinación amorosa, que culmina en las Soledades de Góngora», Estudios dedicados a Menéndez. Pidal, Madrid, C.S.I.C., 1952, III, pp. 457-458.
} 
he pasado, I la divina razón puesta en olvido, I conozco que piedad del cielo ha sido I no haberme en tanto mal precipitado». En los tercetos, la ceguera del pasado se opone a la capacidad de ver del presente; para ello, Lope recurre al concepto vida pasada-laberinto, en unos versos sin parangón en la lírica española del XVII:

Entré por laberinto tan extraño,

fiando al débil hilo de la vida

el tarde conocido desengaño,

mas de tu luz mi oscuridad vencida,

el monstro muerto de mi ciego engaño,

vuelve a la patria, la razón perdida.

Del concepto vida-laberinto pasamos al de yo-monstruo; esta asociación remite al relato mitológico de Ariadna y el Minotauro. De nuevo la luz divina, como en la Introducción de las Rimas sacras, es capaz de imponerse, en este caso sobre la «oscuridad» del pasado ${ }^{12}$. El papel heroico que desempeña Teseo en la historia mitológica no recae en este caso sobre el yo poético.

Lope construye su primer soneto tomando como referencia dos lugares comunes de la literatura profana: el primer soneto de Garcilaso y la historia del Minotauro ${ }^{13}$. Pero de la mitología se extraen «objetos» de referencia, como son el laberinto y el monstruo, con los que se establecen nuevas correspondencias. Según este primer soneto de las Rimas sacras, ha sido la luz divina la que ha matado al monstruo que se identifica con el «ciego engaño» del yo. Como es lógico, luz y oscuridad desempeñan un importante papel en el desarrollo del tema de la ceguera.

\footnotetext{
${ }^{12}$ La idea de camino negativo relacionada con el laberinto se encuentra también en el Romancero espiritual (1612) de Valdivielso: «Mirad que el amor lascivo I es un laberinto ciego, I con entrada y sin salida I por parecerse al infierno», ed. de José María Agurirre, Madrid, Espasa-Calpe, p. 42, y en otros autores de poesía religiosa del XVII. Estos aspectos los estudiamos en la tercera parte de nuestra tesis doctoral Los Soliloquios de Lope de Vega: paratexto, género, intertextualidad y edición crítica, ya citada.

${ }_{13}$ Para subrayar la importancia de los sonetos-prólogo tanto en la tradición petrarquista como en el petrarquismo vuelto a lo divino, nótese que este soneto I de las Rimas sacras, por una parte, comienza con una rescritura de los dos primeros versos del soneto I de Garcilaso; por otra, remite al primer soneto de las Rimas de Lope de Vega (1602). En este soneto I, son los pensamientos, y no el yo poético, los que se pierden en el laberinto del Minotauro: «Versos de amor, conceptos esparcidos, I engendrados del alma en mis cuidados, I partos de mis sentidos abrasados, I con más dolor que libertad nacidos; I expósitos al mundo, en que perdidos, I tan rotos anduvistes y trocados, I que sólo donde fuiste engendrados I fuérades por la sangre conocidos. I Pues que le hurtáis el laberinto a Creta, I a Dédalo los altos pensamientos, I la furia al mar, las llamas al abismo, I si aquel áspid hermoso no os aceta, I dejad la tierra, entretened los vientos, I descansaréis en vuestro centro mismo». Cito por la edición de Antonio Carreño, LOPE DE VEGA, Poesía selecta, Madrid, Cátedra, 1984, p. 231.
} 
No es Lope el único que utiliza el concepto vida-laberinto en un contexto religioso. En el emblema II del «liber secundus» de Pia desideria, la famosa colección obra del jesuita Hermano Hugone (1624), el laberinto se identifica con la perdición del hombre que no cuenta con la ayuda de Dios ${ }^{14}$; en el grabado, en medio de un laberinto, se encuentra la figura que representa al alma humana, y la figura que representa al amor divino tiende, desde el cielo, un hilo al alma, que le permitirá escapar, mientras que a su lado, otra figura humana, con las vestiduras propias de los ciegos y un perro como guía, recorre el laberinto sin posibilidad alguna de encontrar la salida.

Se puede establecer un paralelismo entre el primer soneto de las Rimas sacras y el emblema de Pia desideria, basado en el concepto vida humana-laberinto. Frente al «débil hilo» de la vida que aparece en el soneto de Lope, el amor divino proporciona al hombre un «hilo» con el que éste puede emprender el camino de regreso, dejando atrás la ceguera ${ }^{15}$. En ambos casos, el hombre, al contrario que Teseo, no puede escapar del laberinto por sí mismo.

Continuamos con el análisis de los primeros sonetos de las Rimas sacras, en los que el arrepentimiento del yo poético se expresa mediante numerosas alusiones al tema de la ceguera ${ }^{16}$. En el soneto III, la introspección está íntimamente relacionada con el sentido de la vista: «Entro en mí mismo para verme, y dentro I hallo, ay de mí, con la razón postrada, I una loca república alterada, I tanto que apenas los umbrales entro». Una vez ha salido del laberinto en el que estaba preso, el yo poético «ve» su interior, aunque se percibe cierto temor a la hora de enfrentarse a su pasado. Buena parte de la poesía religiosa del XVII está condicionada por los tratados de meditación que especifican cómo debe llevarse a cabo el análisis de los propios pecados ${ }^{17}$, pero también es cierto que dicha poesía

${ }^{14}$ Citamos por la siguente edición: Pia desideria, Antuerpiae, apud Henricum Aertssens, 1659, Biblioteca Histórica. Universidad Complutense de Madrid, signatura 738.

${ }^{15}$ Compárese el emblema de Pia desideria con los siguientes versos de los Avisos para la muerte, incluidos en un romance de Antonio Barbosa: «Mi vida ha sido confusa I de culpas vn laberinto, I donde perdí muchas vezes I de vuestra piedad el hilo». Citamos por la siguiente edición: Avisos para la muerte, escritos por varios ingenios de España, publicados por Don Luis de Arellano, Madrid, 1659, B.N.M. R / 13664 (fol. 117), aunque la primera edición de esta obra es de 1634. Como venimos observando, el enamorado «ciego» de la tradición petrarquista da paso al pecador «ciego» en la tradición de la poesía religiosa; el mismo Barbosa en el mismo romance: "Tan ciego y porfiado | seguí la voz de los vicios, | que aunque el pecar es flaqueza I en mí pareció capricho», (fol. 117v).

${ }^{16}$ Sobre el orden y los diferentes grupos poemas de esta colección, véase el estudio de Yolanda Novo, Las Rimas sacras de Lope de Vega: disposición y sentido, Universidad de Santiago de Compostela, Servicio de Publicaciones e Intercambio Científico, 1990.

${ }^{17}$ Compárese en soneto de Lope que acabamos de citar con en capítulo I de la Guía de pecadores de Fray Luis de Granada, en el que se dice que los hombres «ni tienen 
religiosa se construye sobre los modelos de introspección popularizados por la poesía petrarquista; en este caso, el soneto de Lope parece una continuación a lo divino del «Cuando me paro a contemplar mi estado» ${ }^{18}$.

Más explícitamente, en el soneto $\mathrm{V}$, encontramos de nuevo la ceguera del yo, situada en el pasado: "Qué ceguedad me truxo a tantos daños? I Por dónde me llevaron desvaríos, I que no traté mis años como míos, I y traté como propios sus engaños?». El motivo se convierte en una idea recurrente en el inicio de las Rimas sacras, puesto que en el soneto VII se lee: «Quién sino yo, tan ciego huuiera sido, I que no viera la luz? Quién aguardara I a que con tantas vozes le llamara, I aquel despertador de tanto oluido?». La ceguera del yo no se expresa ya mediante la imagen del laberinto, como en el soneto I, sino transformando a lo divino el tópico del peregrino de amor, incapaz de seguir su camino con paso firme.

Según los sonetos iniciales de las Rimas sacras, la ceguera ha quedado superada y pertenece al pasado. Pero en la religión, como señala Bruce Wardropper, no hay victorias permanentes, y el hombre debe recomenzar una y otra vez el mismo camino que lleva desde la condena a la salvación ${ }^{19}$. Se produce un continuo trasiego entre la ceguera y la capacidad de ver. El yo recupera la visión, pero esto no quiere decir que la conserve eternamente. Lope plantea este problema en la «Canción a la muerte de Carlos Félix», incluida en las Rimas sacras:

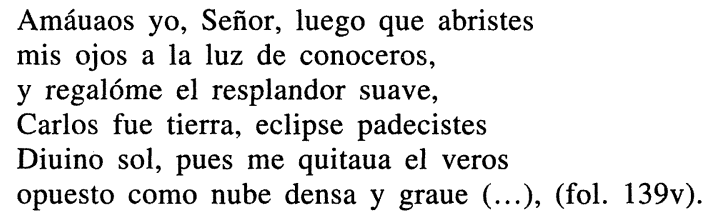

Aunque en las Rimas sacras se vea la literatura profana, desde la atalaya de la conversión, como un error de juventud, Lope seguirá dedicándose a las letras humanas hasta el final de su vida ${ }^{20}$. No hay que olvidar que $L a$ Dorotea es de 1632, tres años antes de la muerte de Lope.

En el soneto XXXIIII de las Rimas sacras, se lleva a cabo una transformación de aquellos sonetos de la tradición petrarquista en los que se

espacio, ni corazón para entrar un poco dentro de sí mismos, y abrir los ojos a la consideración de todo esto», Madrid, Biblioteca de Autores Cristianos, Espasa-Calpe, 1966, p. 17.

${ }_{18}$ Véase a este respecto, el artículo de Eberhard Müller-Bochat, «Técnicas literarias y métodos de meditación en la poesía sagrada del Siglo de Oro», en Actas del Tercer Congreso Internacional de Hispanistas, México, El Colegio de México, 1979, pp. 611-617.

${ }^{19}$ En Historia de la poesía lírica a lo divino en la cristiandad occidental, Madrid, Revista de Occidente, 1958, p. 20.

${ }^{20}$ El rechazo temporal de la literatura profana se hace patente en el soneto XIX de las Rimas sacras, que comienza: "Aquí cuelgo la Lyra que desamo I con que canté la verde Primauera I de mis floridos años, y quisiera I romperla al tronco, y no colgarla en ramo». 
acumulaban una serie de definiciones del amor: «Llamé mi luz a la tiniebla escura, I gloria a mi pena, a mi dolor consuelo, I prouecho al daño, y al infierno cielo, I qué ciego error, qué bárbara locura? (...) Ay loca ceguedad, quál me pusieras, I si fiado de luz tan mentirosa, I eterna noche de mis ojos fueras». Cuando Lope escribe «llamé (...) provecho al daño, y al infierno cielo», alude al famoso soneto que él mismo publicó en las Rimas (1602), CXXVI, en el que se define el amor humano como «olvidar el provecho, amar el daño; I creer que el cielo en un infierno cabe». Como sucedía en el soneto I de las Rimas sacras, la poesía religiosa se construye sobre el modelo de la poesía petrarquista; la ceguera «a lo humano» da paso a una ceguera «a lo divino». En el caso de Lope, el estudio de la intertextualidad es especialmente interesante, pues Lope se permite volver a lo divino sus propios poemas. Ningún autor de poesía religiosa del XVII tiene a sus espaldas una trayectoria poética «a lo humano» tan importante como la de Lope a la altura de 1614 . Veamos ahora cómo se consigue escapar de la ceguera en la literatura religiosa.

\section{LA LLAMADA DIVINA}

El yo de la poesía petrarquista no es capaz de recuperar la visión por sí solo. De entre los muchos ejemplos que podríamos aducir, citamos un soneto de Herrera:

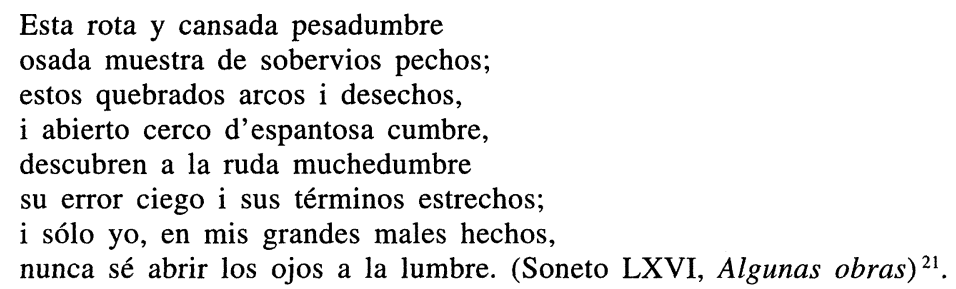

Esto es así porque el yo poético no cuenta con la ayuda de Dios ${ }^{22}$. Por el contrario, en la literatura religiosa, Dios llama al hombre, y lo ayuda a escapar de la oscuridad ${ }^{23}$. El tema se convierte en un motivo literario, sujeto

\footnotetext{
${ }^{21}$ Poesía castellana original completa, p. 451.

${ }^{22}$ Aunque en la poesía moral de Herrera, es la «virtud» quien consigue sacar al yo poético de su error: «D'aquel error en que viví engañado I salgo a la pura luz, i me levanto I tal vez del peso que sufrí cansado (...) | Sola, virtud, tú sola puedes tanto I qu'el gozo dar perpetuo i bien seguro I puedes, si en amor tuyo me levanto», Algunas obras, Poesía castellana original completa, 439.

${ }^{23}$ En las Confesiones de San Agustín, antes de que se produzca la conversión, Dios permite que San Agustín se vea a sí mismo; «y porque yo me había echado tras las espaldas por no verme, vos me poníades a mí delante de mí para que viese cuán feo era, cuán descompuesto, cuán sucio, lleno de manchas y llagas: yo me veía y me espan-
} 
a numerosas recreaciones, de manera que en ocasiones, como sucede en los Soliloquios de Lope, se ofrecen distintas explicaciones sobre cómo despierta el yo a una nueva vida ${ }^{24}$.

La llamada divina tiene en las Confesiones de San Agustín el precedente más destacado. Dios no se dirige directamente al yo, sino que el proceso es más complejo. En el capítulo 12 del libro octavo, San Agustín oye una voz del cielo que le dice "Toma y lee": «Esto decía y lloraba con un corazón contrito y muy amargo; y, estando en esto, oigo una voz de la casa más vecina con un cantar que decía (y lo repetía muchas veces, como su fuera de un niño o una niña): "Toma y lee, toma y lee"» (p. 193). La llamada divina no contiene ningún mensaje; éste se halla en el fragmento de la Biblia que San Agustín lee a continuación:

Así que con paso presurado volví al lugar donde estaba asentado Alipio y yo había dejado el libro de las epístolas' de san Pablo cuando me levanté, toméle, abríle, leí callando el primer capítulo que hallé y en él estas palabras: No en comidas y bebidas, no en camas y deshonestidades, no en porfías ni contiendas, mas vestíos de N. S. Jesucristo, y no tengáis demasiado cuidado de vuestra carne, ni sigáis sus apetitos; y no quise pasar adelante, ni fue menester, porque luego, en leyendo esta sentencia, como un rayo de luz que penetró mi corazón, todas las tinieblas de mis dudas desaparecieron. (p. 194).

Es la lectura, y no la llamada divina, lo que precipita la conversión ${ }^{25}$. Pero San Agustín lee un pasaje determinado de la Biblia porque oye una miste-

taba, y no tenía adónde huir de mí y, cuando procuraba desviar los ojos de mí mismo por no verme, con lo que Ponticiano iba contanto, vos tornábades a poner mi faz delante de mí y a hacer que en ella, como en un espejo, me viese y conociese y aborreciese mi maldad», Citamos por la siguiente edición: Confesiones, Introducción de Josep Maria Rovira Belloso, traducción de Pedro Ribadeneyra (libros 1 a 11) y Ángel Custodio Vega (libros 11 a 13), Barcelona, Planeta, 1993, (p. 184). Quizás en este pasaje se inspire Gracián en el Criticón, crisi VIII, en el que El Prudente saca un espejo para que se vea en él Ardenio, el cual exclama: «Veo un monstruo, el más horrible de mi vida, porque no tiene pies ni cabeza... ¡Quita, quítamele de delante, que moriré de espanto!», citado por Green, España y la tradición occidental, IV, p. 68.

${ }^{24}$ En la Introducción de los Soliloquios no se dice por qué despierta el yo poético, ni tampoco se tiene certeza de que el despertar sea real: «Del deleyte, en que dormidos, I tantos años se olvidaron, I parece que despertaron I todos mis cinco sentidos».

${ }^{25}$ San Agustín, como es bien sabido, es el primer autor que desarrolla la vena introspectiva y autobiográfica en la literatura moderna. Sobre su importancia en el desarrollo del género del ensayo, véase Jesús Gómez, El ensayo español, 1. Los orígenes: siglos XV a XVII, Barcelona, Crítica, 1996. También tiene San Agustín una importancia decisiva en el desarrollo del género del soliloquio, como estudiamos en la segunda parte de nuestra tesis doctoral: Los Soliloquios de Lope de Vega: paratexto, género, intertextualidad y edición crítica. Esta segunda parte será publicada próximamente por el Servicio de Publicaciones de la U.A.M., con el siguiente título: El género del soliloquio en la literatura hispánica (desde san Agustín a Lope de Vega). Véase también el artículo de Jesús Gómez, «El soliloquio de tradición agustiniana como límite del diálogo», Revista de Literatura, LXVI, 131 (2004), pp. 23-47. 
riosa voz del cielo que le empuja a ello; sin la llamada divina, por tanto, no se habría producido la conversión.

Es curioso, sin embargo, que San Agustín lea precisamente las epístolas de San Pablo, puesto que este santo, que antes de convertirse se llamaba Saulo, vivió, como San Agustín, buena parte de su vida alejado del cristianismo. La conversión de Saulo consiste en que la luz divina lo ciega:

Sucedió que, yendo de camino, cuando estaba cerca de Damasco, de repente le rodeó una luz venida del cielo, cayó en la tierra y oyó una voz que le decía: Saúl, Saúl, ¿por qué me persigues? Él respondió: ¿quién eres, Señor? Y él: Yo soy Jesús, a quien tú persigues. (...) Saulo se levantó del suelo y, aunque tenía los ojos abiertos, no veía nada. Le llevaron de la mano y le hicieron entrar en Damasco. Pasó tres días sin ver, sin comer y sin beber. (Hechos de los apóstoles, 9,3$)^{26}$.

La ceguera de Saulo finaliza cuando Anaías, enviado por Jesús, acude a visitarle:

Fue Anaías, entró en la casa, le impuso las manos y le dijo: «Saúl hermano, me ha enviado a ti el Señor Jesús, el que se te apareció en el camino por donde venías, para que recobres la vista y seas lleno del Espíritu Santo». Y al instante cayeron de sus ojos unas como escamas, y recobró la vista; se levantó y fue bautizado. Tomó alimento y recobró las fuerzas. (Hechos, 9, 17)

La llamada divina, paradójicamente, consiste en una ceguera enviada por Dios, de la que se escapa cuando Dios interviene de nuevo. Como en el caso de San Agustín, Saulo, pasa de perseguir a los cristianos a difundir la palabra de Dios. También en ambos casos se precisa el momento en el que el santo recupera la visión.

Por el contrario, en los Soliloquios de Lope, el lector se ve abrumado por una serie de explicaciones distintas, de modo que no queda claro cómo se produce el despertar del yo ${ }^{27}$. Encontramos en los Soliloquios lopescos dos variantes diferentes de la llamada divina. La primera que estudiamos consiste en que Cristo se dirige directamente al yo literario en un pasado indeterminado, en el soliloquio III $^{28}$ :

${ }^{26}$ Sagrada Biblia, Biblioteca de Autores Cristianos, Madrid, duodécima edición, 1957.

${ }^{27}$ En el soliloquio III parece que el yo despierta tras haber sido «mirado» por Cristo. «Notable me la da acordarme de los desatinos que passaron por mis sentidos mientras que no me miraron essos soberanos y dulces ojos, como al Apóstol que os estava negando. Por mis ojos passaron vanas hermosuras, flores que nacen al alva y a la noche mueren; por mis oídos locas palabras, y por los demás sentidos cosas que por no ofender vuestra limpieza aun no las osa rebolver mi memoria». Como estudiamos más adelante, si el pecado ha entrado por los ojos, tendrá que ser purgado con las lágrimas de éstos.

${ }^{28}$ Esto se relaciona con el soneto XIV de las Rimas sacras, que comienza «Pastor que con tus silbos amorosos I me despertaste del profundo sueño (...)». Si Cristo es pastor, el despertar del yo se produce como consecuencia de los «silbos» con los que Cristo le llama. También con el soneto XV de la misma colección, en el que encontra- 
Bendito sea vuestro nombre, piadoso Hijo de Dios, que de tales peligros me sacastes, y que como a otro Lázaro de la sepultura de mi eterna muerte me dixistes: "Ven fuera, miserable, a la luz de la eterna vida». Mas, ¡ay Señor!, aora se me acuerda lo que tardé en desligarme la mortaja de las costumbres que me cercavan todo.

Esta llamada es una transformación de la que tiene lugar en los Soliloquios apócrifos de San Agustín, obra fundamental en el desarrollo del género del soliloquio:

Di a este humilde sieruo y a este mísero esclauo tuyo que Señor eres en mí: y atronaste con vna gran boz en la oreja interior de mi coraçón: y rompiste mi sordedad y oý tu boz, y vi tu luz y alumbraste mi ceguedad y conocite por mí, Dios. Por esso diré que te conoscí. (fol. 108r) ${ }^{29}$.

Según los Soliloquios pseudoagustinianos, el hombre necesita obligatoriamente la llamada de Dios para despertár ${ }^{30}$. Esta pasividad ante la gracia divina se relaciona, como señaló $\mathrm{M}$. Bataillon, con las corrientes reformistas (quietismo, alumbrados, místicos) que aparecen en la España del Renacimiento ${ }^{31}$.

La otra variante de la llamada divina que aparece en los Soliloquios de Lope concuerda más con la doctrina contrarreformista. Se trata de considerar que Cristo o Dios no tienen que dirigirse directamente a los seres humanos para que éstos despierten de su ceguera. El hombre puede «despertar» si sabe interpretar adecuadamente los acontecimientos de su vida, según se lee en el Confesionario breue y muy provechoso para los penitentes, de Francisco de Alcocer:

mos de nuevo una llamada directa de Cristo al yo poético: «Quántas vezes Señor me auéis llamado, I y quántas con vergüença he respondido, I desnudo como Adán, aunque vestido, I de las hojas del Árbol del pecado».

${ }^{29}$ Citamos por la siguiente edición: Meditaciones, Soliloquio, Manual, traducidos por Pedro Rivadeneira, Medina del Campo, 1553, B.N.M. R/2817 (fol. 108r).

${ }^{30} \mathrm{Si}$ bien en la literatura religiosa la llamada divina despierta al yo, en la literatura profana el yo poético puede permanecer toda su vida en la tiniebla, como en el soneto XIIII de Herrera, p. 372: «Dó vas? ¿Dó vas, cruel? ¿Dó vas? Refrena, I refrena el presuroso passo, en tanto I que de mi dolor grave el largo llanto I a abrir comiença esta honda vena. I Oye la boz de mil suspiros llena, I i de mi mal sufrido el triste canto, I que no podrás ser fiera i dura tanto I que no te mueva esta mi acerba pena. I Buelve tu luz a mí, buelve tus ojos, I antes que quede oscuro en ciega niebla», I Dezía, en sueño o en ilusión perdido. I Bolví, halléme solo i entre abrojos, I i, en vez de luz, cercado de tiniebla, I i en lágrimas ardientes convertido». La voz que escucha el yo no es la divina que lo saca de su error, sino la suya, que se dirige inútilmente a la dama. Los ojos de la dama podrían sacar al yo de la oscuridad, pero esto no sucede.

${ }^{31}$ Marcel Bataillon, Erasme et l'Espagne. Recherches sur l'histoire spirituelle du XVIe siècle, Paris, E. Droz, 1937, ampliada y traducida por Antonio Alatorre, Fondo de Cultura Económica, México, 1950; $2^{\mathrm{a}}$ edición, corregida y aumentada, 1966; $5^{\mathrm{a}}$ reimpresión, Madrid, 1995. p. 47. Véase la segunda parte de nuestra tesis doctoral, ya citada. 
El pecador, a quien dios por su bondad toca con su mano, y previene con su gracia, enviándole sanctas inspiraciones, dándole alguna graue enfermedad, visitándole con la muerte de algún hijo muy querido, representándole el día del juicio, la muerte, la pena infernal, o gloria celestial, enviándole algún predicador, o doctor, que con sus palabras, vida y ejemplo le mueua a boluerse a él, y dessar la mala vida pasada (...)» (Salamanca, Iuan de Cánoua, 1558: fol. $28 \mathrm{r})^{32}$.

Dios, por tanto, según la doctrina contrarreformista, puede advertir al hombre de múltiples maneras. Se supone que la enfermedad o la «muerte de algún hijo» son avisos divinos, que hacen que el yo reflexione sobre su existencia y vuelva sus ojos a Dios. En el prólogo de los Soliloquios, cuando se relata el despertar de Padecopeo, autor supuesto de los Soliloquios, encontramos una huella literaria de este segundo tipo de llamada divina:

En el discurso de algunos años, que vencido desta passión dexó dormir los sentidos, que ya como soldados de Ulisses tenían en el palacio de Circe diversas formas, le previnieron sucessos tristes la perdición del alma, y despierto a los rayos de aquel Sol de justicia, por cuya Aurora tantos peregrinos han hallado la luz de la verdad en la noche de su engaño, con firme resolución se despidió del mundo. (La cursiva es nuestra) ${ }^{33}$.

La llamada divina directa sólo se menciona en el soliloquio III, como ya hemos visto. En cambio, este segundo tipo de llamada divina está también presente en el soliloquio I:

Y eslo esto tanta, que ha pocos días que quisistes vos que una de las que me agradaron viniesse a morir adonde yo la viesse, tan miserable, que no sólo avía perdido la hermosura, mas también el entendimiento, para que viesse yo el fuego que me pareció luz, tan fea y abominable ceniza, que me abriesse más de veras los ojos a la contemplación de nuestra común miseria, y que en essos mismos días viesse, Dios mío, una virgen difunta sobre un túmulo, descubierto el rostro, las manos con una palma y la cabeça con una guirnalda de flores, con tan divina hermosura, que en los labios, que estavan vertiendo risa, se engañava la atención de los que la miravan, y sólo por la mortaja, paños negros y hachas encendidas constava de su muerte; pero qué mucho que tuviesse hermosura aquel dichoso cuerpo, cuya alma entonces estava recibiendo de vuestras manos, Jesús dulcíssimo, la corona de gloria que para vuestras esposas tenéis guardada. (La cursiva es nuestra).

Dos hechos «abren los ojos» del yo: la muerte de una antigua amante y la

${ }^{32}$ Biblioteca Histórica. Universidad Complutense de Madrid, signatura 983.

${ }^{33} \mathrm{La}$ referencia a la Circe es frecuente cuando se trata el tema de la llamada divina, como se aprecia en el soneto XXXIIII de las Rimas sacras: "Y mis sentidos de aquel bien remotos, I que la inmortalidad del alma espera, I durmieron mi florida Primavera, I de la razón los memoriales rotos. I No sólo del veneno la beuida I sueño solicitó, mas de mí tuuo I la mejor parte en bestia convertida. I Circe con sus encantos me detuvo I hasta que con tu luz salió mi vida, I de la costumbre, en que cautiua estuuo». En este caso vuelve a ser la «luz» divina la que consigue despertar al yo poético. 
de una virgen ${ }^{34}$. La vida, de esta manera, se convierte en un enigma que el hombre debe descifrar. Cuando algo sucede, esconde quizás un mensaje divino que el hombre debe interpretar. Pero encomendarse exageradamente a la interpretación de los designios de la divinidad convertiría la existencia en algo oscuro, ambiguo, mientras que la doctrina contrarreformista pretende ofrecer un mensaje claro y conciso. Así, en los Ejercicios ignacianos, el lector sabe que puede escapar de la ceguera si se lo pide a Cristo, pues le serán concedidas todas sus demandas si éstas son formuladas de manera adecuada.

\section{LA LUZ DE LOS EJERCICIOS ESPIRITUALES}

San Ignacio, en los Ejercicios, se sitúa en una posición diferente de las que hemos venido estudiando. No pretende que el hombre espere la llamada divina sino que sea él mismo quien tome la iniciativa y emprenda por sí sólo el camino hacia Dios. En los Ejercicios, el hombre comienza por asumir sus pecados; el despertar se irá produciendo a medida que se avance en la meditación. Al hilo de ésta, el que practica los ejercicios debe llevar a cabo una serie de coloquios dirigidos a Cristo ${ }^{35}$; las instrucciones que da San Ignacio para el coloquio tienen gran repercusión en la literatura religiosa del siglo XVII, y parten de la premisa de que Cristo concederá al hombre todo lo que éste le pida.

En el coloquio de los Ejercicios, el yo debe pedir «alguna gracia» a Cristo. Esto se transforma en literatura en los Soliloquios de Lope, en los que el yo demanda a Cristo que le abra los ojos (sol. IV): « $i$ Ay ciegos errores míos! I Abridme, Señor, los ojos, I para ver vuestros enojos, I y entender mis desvaríos». El yo de los Soliloquios se identifica con los ciegos de la Biblia (Mateo, 9, 27), quienes tenían los ojos cerrados y perseguían a Jesús para que les sanara: «Entonces tocó sus ojos, diciendo: hágase en vosotros según vuestra fe. Y se abrieron sus ojos» ${ }^{36}$. Estas peti-

\footnotetext{
${ }^{34}$ En los Soliloquios las alusiones a la vida de Lope son difusas; aun así, parece que en el fragmento anterior se podría estar transformando en literatura dos hechos conocidos de la biografía lopesca. Por una parte, la locura de Marta de Nevares, que se convertiría en su «muerte»; por otra, la entrada de Marcela, la hija de Lope, en el convento de las Trinitarias, que tuvo lugar en 1623 y a la que Lope dedica una composición en La Circe (1624). Las dos muertes ficticias hacen que el yo literario «abra los ojos».

35 «El colloquio se hace propiamente hablando así como vn amigo habla a otro o vn siervo a su señor, quando pidiendo alguna gracia, quando culpándose por algún mal hecho, quando comunicando sus cosas y queriendo consejo en ellas; y decir vn Pater noster", Ejercicios espirituales, Texte autographe des Exercices spirituelies et documents contemporains (1522-1615), ed. de É. Gueydan, Paris, Desclée de Brouwer, 1986, p. 86.

${ }^{36}$ Sagrada Biblia, Biblioteca de Autores Cristianos, Madrid, duodécima edición, 1957. También en el Salmo 118, 18: «Abre mis ojos para que contemple I las maravillas tu ley». En la Segunda parte del desengaño del hombre, de Lope de Vega, Madrid, Miguel
} 
ciones encajan en el desordenado sistema del género del soliloquio, puesto que, si las tomáramos al pie de la letra, querría decir que hasta el soliloquio IV el yo poético ha permanecido en la oscuridad ${ }^{37}$.

En el comentario en prosa al soliloquio IV, se desarrolla la misma petición con más detalle:

\begin{abstract}
$¡$ Ay, ciegos errores de mi juventud! Las ignorancias de la cual aquel santo Rey vuestro antecessor os pedía que no os acordássedes dellas, suplícoos pues, Dios mío, Señor mío, deis luz a los ojos de mi entendimiento para que os considere airado, y entienda las ocasiones que os di para que lo estéis. Si os tiemblan las colunas del cielo, ¿qué haré yo pensando que sois juez de muertos y vivos?, y más si pongo los ojos en el libro de mis maldades, donde a la pluma del fiscal riguroso no se le ha de olvidar un átomo. ¡Ay, Dios!, tantas obras feas, tantas palabras locas, tantos pensamientos vanos, ¿qué será de mí? (La cursiva es nuestra).
\end{abstract}

El yo petrarquista no era capaz de salir de su error ${ }^{38}$; en la literatura religiosa esto sí es posible, pues Dios o Cristo escuchan las súplicas del hombre.

Frente al desorden de los Soliloquios de Lope, en la emblemática, el tema de la ceguera se sitúa de nuevo al inicio de la lectura. El «liber primus» de Pia desideria, obra del jesuita Herman Hugone a la que ya nos hemos referido, comienza con un grabado que podemos describir así: en medio de la noche, la figura que representa al amor divino guía al alma con una lámpara; el mote está tomado de Isaías, 26: «Anima mea desiderauit te in nocte». Nótese la importancia de este emblema; el lector de la colección va a dejarse conducir a través de una serie de grabados; cada uno de ellos explicado por una frase bíblica, especialmente de los Salmos o del Cantar $^{39}$. Cada emblema va seguido de unos versos, más una medi-

Serrano de Vargas, 1615, incluida en el Confessionario general de Francisco de Soto, Cuenca, Salvador de Viader, 1622, B.N.M. R/9791, el yo poético se dirige a su alma (y al lector), sin pedir ayuda a Cristo: «Antes que llegue la final sentencia, I tus soñolientos ojos abre y mira, I que son la vida, y el morir penoso, I término breue, tránsito forçoso», (fol. 6v). El yo asume el papel de director espiritual, y guía a su alma (y al lector) en el camino de la meditación.

${ }^{37}$ Como muestra del desorden de los Soliloquios de Lope, en el III el yo poético se expresa como si ya hubiera recuperado la visión: «iAy de mí, qué sin razón I passé la flor de mis años I en medio de los engaños I de aquella ciega afición!».

${ }^{38}$ Compárese con el soneto LXII de las Poesías de Herrera que se publican en 1619: «Vos, en vuestro esplendor onráis los ojos; I yo voy a do mi ciego error me llama; I vuestro Sol vos regala y vos inflama; | yo en lenta pena enciendo mis enojos», p. 555.

${ }^{39}$ Herman HugONE, autor de Pia desideria, comenta el primer grabado con las siguientes palabras de los Soliloquios apócrifos de San Agustín: «Vae tempori quando non cognoscebam te! Vae Caecitati illi quando non videbam te? Illuminasti me lux mundi, et vidi te», Soliloquios, cap. 31. Y también: «Caecus eram, et caecicitatem amabam, et ad tenebras per tenebras ambulabam. Quis me eduxit? Ubi eram homo caecus sedens in tenebris et umbra mortis?»(p. 3). Según Hugone, procede de los Soliloquios, cap. 38. No debemos confundir los Soliloquios auténticos de San Agustín, que son en realidad 
tación en prosa en la que se introducen fragmentos de otras obras. Sobre estos textos, con la ayuda visual del grabado, el lector debe desarrollar su propia meditación. Para el primer emblema, Hugone recurre a los Soliloquios apócrifos de San Agustín:

Vocati enim me nomine tuo, intonasti de super voce grande in interiores aurem cordis mei; Fiat lux, et facta est lux; et discessit nubes magna, et liquefacta est nubes tenebrosa, quae operuat oculos meos, et vidi lucem team, cognouit vocem team, et dixi: Vere Domine tu es Deus meus qui eduxiti me de tenebris, et vmbra mortiset vocasti me in admirabile lumen tuum. (Pia desideria, pp. 3-4).

Es un fenómeno intertextual interesante. En los Soliloquios apócrifos se relata no sólo la llamada divina, sino también las numerosas ocasiones en las que el yo trató en vano de buscar a Dios, sin encontrarlo. ¿Cómo puede una obra como los Soliloquios apócrifos, desorganizada, precursora de las corrientes alumbradas, en la que todo depende de la llamada divina, integrarse en el orden de Pia desideria? La Compañía de Jesús, que combatió los excesos místicos que derivan de los Soliloquios apócrifos, no renuncia a ese tipo de literatura, sino que le da una función diferente. El fragmento de los Soliloquios apócrifos está incluido al principio de una meditación ejemplar que se estructura alrededor de una imagen; es una parte de un todo perfectamente equilibrado ${ }^{40}$. El lector de Pia desieria se enfrenta al tema de la llamada divina al principio de la obra; es el primer paso para recorrer las tres partes en las que se divide el libro: «gemitus», «vota» y «suspiria». Las exclamaciones afectivas que se exponen en la meditación en prosa de Pia desideria, aunque procedan de los Soliloquios apócrifos de San Agustín, se incluyen para estimular la imaginación del lector, como ejemplo de coloquio hacia Dios en el que interviene la voluntad. La ceguera del yo, en Pia desideria, se trata al principio del volumen; es una obra en la que se sigue un camino meditativo claro, lineal, completamente opuesto al caos de los Soliloquios apócrifos.

En Pia desideria, como en las obras meditativas de la Compañía de Jesús que derivan de los Ejercicios espirituales ignacianos, es determinante, más que la llamada divina, la voluntad del yo. La meditación debe llevarse a cabo a partir de la contemplación de una imagen. Ésta puede ser la del grabado, como es el caso de Pia desideria, o la imagen creada por

un diálogo entre San Agustín y la Razón, con los apócrifos, en los que un yo se dirige a Dios. Véase para estas cuestiones SAN AGUSTín, Escritos atribuidos, ed., introducción y notas de Teodoro C. Madrid, Biblioteca de Autores Cristianos, 2002, p. 301, y la segunda parte de nuestra tesis, ya citada.

${ }^{40}$ En La Naissance du livre moderne, coordinado por Henri-Jean Martin, leemos a propósito de Pia desideria: «Le tout est disposé selon un ordre diachronique qui restitue celui des oraisons des Exercices spirituels», Tours, Éditions du Cercle de la Librairie, 2000, p. 387. 
la «vista de la imaginación» del yo literario, como sucede en los Soliloquios de Lope. Ya no es necesaria la acción de Cristo, sino que basta con el esfuerzo del yo en la contemplación de la imagen de Cristo en la Cruz, como se aprecia en el siguiente fragmento del soliloquio VI:

No es possible, ojos míos venturosos, que aya sido en otra parte que en la santíssima cruz, donde aquel agua divina, última señal de que ya no quedava sangre, os deve de aver clarificado, que essa divina celidonia que cuelga en ella avrá quitado las nieblas a vuestros engaños. Moisés hirió una piedra en Rafidín, de quien salió la fuente refrigerio del sediento Israel, y allí un soldado hiriendo la piedra Christo, nunca más triangular que entonces, clavados los pies juntos, y abiertos y tendidos los braços, sacó del golpe de su lança este divino tesoro para los hombres. Pero vosotros, ojos míos, no penséis que merecistes este divino colirio con que os bañastes; pues cada vez de las muchas que le ofendistes, alanceastes su enamorado coraçón, atrevidos a su difunto pecho.

El yo literario aclara sus ojos gracias al agua que brotó del costado de Cristo tras el lanzazo de Longinos. No hace falta aguardar la llamada divina, ni interpretar el mundo tratando de encontrar indicios de la voluntad de Dios. Basta con contemplar con «la vista de la imaginación», como recomienda San Ignacio, las escenas de la Pasión de Cristo; así es posible que el yo literario salga de la ceguera por sí mismo ${ }^{41}$. Con la técnica de la composición de lugar, el yo asiste a la muerte de Cristo, y así consigue recuperar la visión. Cristo es «divina celidonia» y «divino colirio», puesto que cura los ojos ${ }^{42}$. Este último es un concepto extraño, que seguramente se relacione con el siguiente fragmento del libro séptimo de las Confesiones de San Agustín: «Y con esto, con vuestra mano oculta y medicinal, se iba curando aquella hinchazón mía y sanando la vista de mi alma turbada y confusa con el colirio de mis saludables dolores» ${ }^{43}$.

${ }^{41}$ Pero los Soliloquios también tienen un lado humano, puesto que si en los Ejercicios se deben considerar detenidamente los pecados, en la jaculatoria XCI el yo expresa su miedo: «No ay cosa, amor mío, que me ponga más temor que bolver la cabeça a los peligros de que me ha sacado tu misericordia».

${ }^{42}$ Quizás se relacione con el Salmo 18, que fray Luis traduce así: «Tus leyes alcool de nuestros ojos», cito por Romancero de palacio, Cleveland, 1996. p. 305. En el salmo 18 se lee: «claro el mandamiento de Yavehh, I luz de los ojos». Quizás a esto se refiera Lope en El Peregrino en su patria, en el auto de La Maya: «Conoce tu dignidad, I Alma, y mira que los ojos I ven con mayor claridad, I cuando están libres de enojos, I y de alguna enfermedad. I Lo que te importa previsto, I limpios los ojos tendrás, I que en el sol, que te conquisto, I si limpia del mundo estás, I mejor mirarás a Cristo», Madrid, Castalia, 1973, p. 306.

${ }^{43}$ SAN Agustín, Confesiones, p. 152. En Apocalipsis, 3, se lee: «Collyrio inunge oculos tuos; vt videas». En los Soliloquios de San Buenaventura, que se difunden ampliamente en el siglo XVI, se hace referencia, como en el caso de San Agustín, a las lágrimas que permiten aclarar la visión: «Mas conuiene que sepas que quanto más perfetamente la ceguedad del entendimiento es alimpiada con el lauatorio de la contri- 
Muy lejos queda la actitud del enamorado petrarquista, perdido y ciego en medio del camino de sus amores ${ }^{44}$. En las obras de la Compañía de Jesús, el yo recupera la visión, pero debe utilizarla en una dirección concreta: se trata de ver una y otra vez las mismas imágenes, ya sean físicas (grabados) o mentales. La Pasión debe ser continuamente recreada, para que el ejercitante sienta en su propio cuerpo el dolor de Cristo ${ }^{45}$. De este modo, se consiguen las lágrimas que aclaran la vista. Estas lágrimas no proceden de Dios (como en el fragmento anterior de San Agustín), sino que son resultado de la meditación ${ }^{46}$. Así, en el soliloquio VI el yo literario consigue definitivamente «ver» con claridad, y se dirige a sus ojos en estos términos:

¿Cómo tenéis tanta claridad y tan aguda vista? Ojos, no sé qué me diga de aquesta mudanza vuestra, desta transformación divina, que no ovidiana, ni fabulosa, pues tan de linze os avéis hecho que osáis mirar a Dios en la imagen de su humanidad santíssima.

La ceguera del yo petrarquista ha sido superada, pero las técnicas ignacianas restringen lo que el hombre tiene que «ver»; podemos considerarlo un nuevo modo de «ceguedad» ${ }^{47}$. En la jaculatoria LVII, encontramos la siguiente

ción, tanto más claramente se contempla el beneficio de la diuina reparación. El pecado según Sant Augustín dize, es tiniebla que embotó el entendimiento: y por el hombre de dentro es del todo escurecido. Donde necessario es que los ojos mentales tanto más diligentemente sean de la tiniebla del pecado continuemente alimpiados con lágrimas de compunción», Alcalá de Henares, Miguel de Guía, 1525, B.N.M. R / 5003, (fol. xiv,r).

${ }^{44}$ Así se aprecia en el sol. I: « $\mathrm{O}$, qué divinas colores I os haze essa sangre fría! I ¡O, cómo estáis, vida mía, I para deziros amores! I Pero ya que me provoco, I con veros a tal dolor, I harto os he dicho, Señor, dexadme llorar un poco».

${ }^{45}$ En el soliloquio V, leemos: «Mejor es que a vos os deva, I dulce Jesús, tanto amor, I aunque ver vuestro dolor I a tanto dolor me mueva».

${ }^{46}$ En los Soliloquios de Lope, las lágrimas tienen la capacidad de limpiar los ojos; el soliloquio VI comienza de la siguiente manera: «Ojos ciegos y turbados, I si pecados son venenos, I ¿cómo estáis claros y buenos I después que lloráis pecados?». La ceguera se convierte en claridad gracias al poder de las lágrimas. Los ojos son en cierta medida culpables de los pecados, y con las lágrimas pagan esa deuda, como se aprecia en el soliloquio VI: «Perdido por mis pecados de mi vista, y ganado por vuestra gracia de mi alma (...)». Aunque, en el soliloquio VII, parece que es la Virgen, y no las lágrimas, quien ayuda al yo a escapar de la ceguera: «La estrella que me guió a vos fue vuestra piadossísima Madre, que como es abogada nuestra, y en la mar de nuestras tormentas luze, por escuro que corra el tiempo de nuestra ceguedad, no sé si acertara yo a vos, si con la claridad de su intercessión no os huviera visto».

${ }^{47}$ Roland BARTHES, en su estudio fundamental sobre los Ejercicios espirituales, señala que la «imaginación» ignaciana ligada a la composición de lugar es ante todo una técnica de definir qué es lo que no tiene que ser imaginado: «elle forme un ars obligatoria qui fixe moins ce qu'il faut imaginer que ce qu'il n'est pas possible d'imaginer-ou ce qu'il est impossible de ne pas imaginer. C'est ce pouvoir négatif qu'il faut reconnaître d'abord à l'acte fondamental de la méditation, qui est la concentration: «contempler», «fixer», «me représenter à l'aide de l'imagination», «voir des yeux de l'imagination», 
petición a Cristo: «Pues me llamo esclavo tuyo, ponme tus tres clavos, dos en los ojos y uno en el coraçón». El corazón del yo ya no es traspasado por las flechas del amor, sino por los clavos, representantes del sufrimiento de Cristo; el amor humano ha sido definitivamente sustituido por el divino ${ }^{48}$.

Como conclusión, baste decir que Lope, en su literatura religiosa, confiere un desarrollo notable al tema de la ceguera. Hemos visto el papel que juega el sentido de la vista en la poesía italianizante, y cómo la ceguera del enamorado se convierte en la ceguera del yo pecador. Asimismo, destaca la importancia que tiene la llamada divina como hecho que posibilita (o no) la conversión del yo. Por último, comprobamos que la disciplina de la Compañía de Jesús hace mucho más simple el proceso de recuperar la visión, de manera que las lágrimas se obtienen de manera sistemática, y así se consigue la claridad. La literatura religiosa de Lope, y especialmente los Soliloquios, pueden ser leídos como el testimonio edificante de un yo que consiguió superar la ceguera; el camino recorrido quizás pueda servir de guía para otros, puesto que es ejemplo de una resurrección personal.

«me mettre en face de l'objet», c'est d'abord éliminer, c'est même éliminer continûment (...)», Sade, Fourier, Loyola, París, Seuil, 1971, p. 57.

${ }^{48}$ Sin embargo, la actitud del yo literario recuerda a la del enamorado de la poesía petrarquista en la jaculatoria LXI: «Muchas vezes, Cordero mío, no oso alçar los ojos a mirarte, y entonces parece que me los llevas tú». 


\section{RESUMEN}

El tema de la ceguera en la literatura religiosa de Lope, por Hugo Lezcano Tosca.

En la literatura barroca, el desengaño se convierte en un lugar común que recibe un amplio desarrollo. El desengaño consiste en que el hombre se da cuenta de que lo que ve ve con sus ojos es falso, puesto que las bellezas de la tierra sólo son «vanas sombras». En este artículo se estudia el tema de la ceguera en la literatura religiosa de Lope, teniendo en cuenta tres aspectos diferentes: en primer lugar, se analiza la ceguera del yo de la literatura religiosa como transformación «a lo divino» de la ceguera del enamorado petrarquista. En segundo lugar, se estudia en qué consiste la llamada divina en algunos textos religiosos y literarios, como las Confesiones de San Agustín o los Soliloquios de Lope. Por último, se estudian los métodos que emplea la Compañía de Jesús (composición de lugar, libros de emblemas) para acabar con la ceguera del hombre.

Palabras clave: Ceguera, literatura religiosa, Lope de Vega, petrarquismo, Compañía de Jesús.

\section{ABSTRACT}

In baroque literature, el desengaño is a commonplace that gets a large development. $E l$ desengaño means that man realizes that everything he can see is "vanas sombras». In this article, the question of blindness in Lope de Vega's religious poetry is studied through three different aspects: first, blindness of the self in religious poetry is considered as a transformation «a lo divino» of petrarchist lover blindness. Secondly, the divine call is studied in some literary and religious texts, like Saint August Confessions, or Lope de Vega's Soliloquios. Finally, the different methods used by the Society of Jesus to finish with man's blindness (compositio loci, emblems) are analysed.

Key words: Blindness, religious literature, Lope de Vega, petrarchism, Society of Jesus. 